\title{
Extrinsic functional connectivity of the default mode network in crack-cocaine users
}

\author{
A conectividade funcional extrínseca da rede de modo padrão em usuários de crack-cocaína
}

\section{Diego Lima Nava Martins ${ }^{1}$, Talles Destefani de Souza Valiatti ${ }^{2}$, Júlia D’Ávila ${ }^{2}$, Lucas Freire Ferreira ${ }^{2}$, Edson Kruger Batista $^{3}$, Paulo Rodrigo Bazán ${ }^{4}$, Rodrigo Stênio Moll de Souza ${ }^{5}$, Ester Miyuki Nakamura-Palacios ${ }^{6}$}

Martins DLN, Valiatti TDS, D’Ávila J, Ferreira LF, Batista EK, Bazán PR, Souza RSM, Nakamura-Palacios EM. Extrinsic functional connectivity of the default mode network in crack-cocaine users. Radiol Bras. 2018 Jan/Fev;51(1):1-7.

Abstract Objective: This study aimed to explore the functional connectivity of the default mode network (DMN) in crack-cocaine users, in comparison with that observed in age-matched non-drug-using controls.

Materials and Methods: Inpatient crack-cocaine users who had been abstinent for at least four weeks and age-matched non-drugusing controls underwent resting state functional magnetic resonance imaging. Images were acquired while the subjects rested with their eyes closed. After data preprocessing, DMNs were defined by spatial independent component analysis and seed-based correlation analysis, by chosen regions of interest centered in the ventral anterior cingulate cortex and in the posterior cingulate cortex. Results: The functional connectivity of the DMN determined by independent component analysis did not differ between the crackcocaine users and the controls. However, the seed-based correlation analysis seeking a single metric of functional connectivity between specific brain regions showed that the negative connectivity between the ventral anterior cingulate cortex and the left superior parietal lobule was significantly greater in the crack-cocaine users than in the controls.

Conclusion: The results suggest that selective extrinsic network connectivity of the DMN related to motor and executive function is impaired during crack-cocaine addiction.

Keywords: Substance-related disorders; Magnetic resonance imaging/methods; Brain/physiopathology; Image interpretation, computer-assisted; Functional neuroimaging.

Resu mo Objetivo: Este estudo teve como objetivo explorar a conectividade funcional da rede de modo padrão em usuários de crack-cocaína comparando-a a controles não usuários da mesma faixa etária.

Materiais e Métodos: Usuários de crack-cocaína internados em abstinência por pelo menos quatro semanas e controles não usuários pareados por idade foram submetidos a ressonância magnética funcional em estado de repouso, enquanto descansavam com os olhos fechados. Depois do pré-processamento de dados, a rede de modo padrão foi definida por análise espacial de componentes independentes e análise de correlação baseada em sementes, por regiões de interesse centradas no córtex cingulado anterior ventral e no córtex cingulado posterior.

Resultados: A conectividade funcional analisada por componentes independentes não foi diferente entre os usuários de crackcocaína e os controles pareados por idade. No entanto, a análise de correlação baseada em sementes à procura de uma conectividade funcional métrica única entre regiões específicas do cérebro mostrou uma negatividade significativamente maior da conectividade entre o córtex cingulado anterior ventral e o lóbulo parietal superior esquerdo, quando comparada a controles pareados por idade.

Conclusão: Os resultados sugerem que conectividades extrínsecas seletivas da rede de modo padrão relacionadas a funções motoras e executivas podem estar comprometidas na dependência de crack-cocaína.

Unitermos: Transtornos relacionados ao uso de substâncias; Ressonância magnética/métodos; Encéfalo/fisiopatologia; Interpretação de imagem assistida por computador; Neuroimagem funcional.

Study conducted under the auspices of the Graduate Program in Physiological Sciences, Federal University of Espírito Santo (UFES), Vitória, ES, Brazil. This work was partially supported by the Conselho Nacional de Desenvolvimento Científico e Tecnológico (CNPq)-Grant Nos. 475232/2013-5, 443824/2014-2, and 466650/2014-0 to E.M.N-P.). E.M.N-P. is the recipient of a research fellowship grant from CNPq (Grant No. 304374/2014-8).

1. MD, Department of Internal Medicine, Health Sciences Center, Graduate Program in Medicine, Federal University of Espírito Santo (UFES), Vitória, ES, Brazil.

2. Department of Electric Engineering, Technology Center, Brazilian Research Group on Brain and Cognitive Engineering (BRAEN), Federal University of Espírito Santo (UFES), Vitória, ES, Brazil.

3. MD, MSc, Laboratory of Cognitive Sciences and Neuropsychopharmacology, Graduate Program in Physiological Sciences, Federal University of Espírito Santo (UFES), Vitória, ES, Brazil.
4. Laboratory for Medical Research 44 (LIM-44-Laboratório de Investigação Médica 44), Department of Radiology, University of São Paulo (USP), São Paulo, SP, Brazil.

5. MD, MSc, Department of Internal Medicine, Health Sciences Center, Brazilian Research Group on Brain and Cognitive Engineering (BRAEN), Federal University of Espírito Santo (UFES), Vitória, ES, Brazil.

6. MD, PhD, Graduate Program in Medicine, Laboratory of Cognitive Sciences and Neuropsychopharmacology, Brazilian Research Group on Brain and Cognitive Engineering (BRAEN), Federal University of Espírito Santo (UFES), Vitória, ES, Brazil.

Mailing address: Dra. Ester M. Nakamura-Palacios. Programa de Pós-Graduação em Ciências Fisiológicas, Centro de Ciências da Saúde, Universidade Federal do Espírito Santo. Avenida Marechal Campos, 1468, Maruípe. Vitória, ES, Brazil, 29043900. E-mail: emnpalacios@gmail.com.

Received July 5, 2016. Accepted after revision January 10, 2017. 


\section{INTRODUCTION}

Crack-cocaine has emerged as a substance that readily supplies the active principle (cocaine) through the inhalation of smoke from burning rocks of the substance, typically by means of a pipe ${ }^{(1)}$. How it affects the nervous system remains unknown. However, certain neural circuits are supposedly involved in the establishment and maintenance of drug addiction ${ }^{(2,3)}$. According to Volkow et al. ${ }^{(4)}$, there are four interrelated circuits that are involved in or affected by drug addiction: the reward circuit-involving several nuclei in the basal ganglia, notably the nucleus accumbens of the ventral striatum, and relaying information to the ventral pallidum; the motivation/drive circuit-involving the orbitofrontal and subcallosal cortices, dorsal striatum, and motor cortex; the learning/memory circuitinvolving the amygdala and the hippocampus; and the control circuit-which controls cognitive flexibility and planning, involving the dorsolateral prefrontal cortex, anterior cingulate cortex, and inferior frontal cortex. Many of these brain structures are associated with the default mode network $(\mathrm{DMN})^{(5-7)}$, one of the brain networks seen in resting state functional magnetic resonance imaging (rs-fMRI) studies ${ }^{(8)}$. The DMN is composed of brain regions that are typically deactivated during task demands but exhibit synchronous low frequency oscillation in the resting state ${ }^{(6,7,9)}$. It is believed that the DMN is related to attention and self-monitoring ${ }^{(10)}$, or, more precisely, the general monitoring of sensory information associated with the posterior cingulate and adjacent precuneus, as well as the evaluation of the salience of this information together with the medial and orbitofrontal cortices ${ }^{(9)}$. This provides a new perspective on brain function by addressing the importance of ongoing or intrinsic activity ${ }^{(7)}$.

Previous rs-fMRI studies have identified changes in functional connectivity in individuals who abuse or are addicted to drugs such as cocaine, heroin, morphine, nicotine, alcohol, and caffeine. However, to our knowledge, there have been no such studies involving individuals addicted to crack-cocaine. We hypothesized that the DMN would be affected in crack-cocaine users. Therefore, this study aimed to explore the functional connectivity of the DMN by using independent component analysis (ICA) and seed-based correlation analysis of rs-fMRI data collected from crack-cocaine users and age-matched nondrug-using controls.

\section{MATERIALS AND METHODS}

For this study, we interviewed 38 individuals with crack-cocaine addiction, as defined in the Diagnostic and Statistical Manual of Mental Disorders, fourth edition (DSM-IV), recruited from among those under treatment at a mental health clinic for drug dependence treatment in the state of Espírito Santo, Brazil. Of those 38 individuals, 10 met the inclusion criteria. At the mental health clinic, the subjects were evaluated in a highly restricted and controlled environment. Urine samples were collected for drug testing, and all of the subjects tested negative. We acquired rs-fMRI scans in a $1.5 \mathrm{~T}$ scanner at the Cassiano Antônio de Moraes University Hospital, operated by the Federal University of Espírito Santo. Because of technical problems during the acquisition of the images, data for two of the subjects were excluded from the analysis. Therefore, data for eight crack-cocaine users were included in all analyses.

As a control group, healthy, non-drug-using, agedmatched male subjects were recruited from among the employees of the University Hospital and of the private clinic, as well as from among students at the Federal University of Espírito Santo. The rs-fMRI scans of the control group subjects were acquired in the same scanner as were those of the study group.

The inclusion criteria for the crack-cocaine user group were as follows: being male; being over 18 years of age; meeting the criteria for a clinical diagnosis of crackcocaine dependence, as defined in the symptom checklist for mental disorders of the International Classification of Diseases, 10th revision, and in the DSM-IV; being in stable clinical condition (not requiring hospitalization); being able to read, write, and speak Portuguese; and presenting with no signs or symptoms of severe withdrawal at baseline.

Subjects who were intoxicated with or in withdrawal from a substance other than crack-cocaine were excluded, as were those who had been diagnosed with a psychiatric or physical disorder, including substance abuse disorder and addiction to any substance other than crack-cocaine, nicotine, or caffeine. We also excluded subjects who had been diagnosed with epilepsy or convulsive disorder; those who had experienced delirium tremens during abstinence from crack-cocaine use; those with a history of drug hypersensitivity or adverse reactions to diazepam, other benzodiazepines, or haloperidol; those presenting with any contraindication for MRI, such as electronic implants, metal implants, and claustrophobia, as well as permanent makeup or tattoo received within the last three months; and those with vascular, traumatic, inflammatory, or neoplastic processes detectable by MRI. It should be stated that medications were given to the crack-cocaine users to relieve the symptoms of anxiety and depression that can arise during abstinence.

The study was approved by the Institutional Review Board of the Federal University of Espírito Santo (CAAE Protocol Nos. 19403713.6.0000.5060 and 13528213.2. 0000.5060 ). The study procedures were in strict adherence to the Declaration of Helsinki and in accordance with the ethical standards established by the Committee on Human Experimentation of the Federal University of Espírito Santo, where the study was conducted. All participating subjects gave written informed consent. 
We assessed ten inpatients diagnosed with crack-cocaine dependence and eight non-drug-using controls. To do so, we used a brief structured interview designed to obtain sociodemographic data and information regarding the characteristics of drug use.

\section{MRI}

The rs-fMRI scans were obtained while subjects rested quietly, with their eyes closed but awake. The images were acquired in 1.5 T MRI scanners (Achieva; Philips Medical Systems, Best, the Netherlands), with a specific 8-channel sensitivity encoding head coil (SENSE; Philips Medical Systems), at the radiology center of the Cassiano Antônio de Moraes University Hospital.

Functional images were acquired using a gradient echo echo-planar imaging sequence-repetition time/ echo time (TR/TE): 3000/50 ms; flip angle $=90^{\circ} ; 35$ axial slices; matrix: $64 \times 64$; field of view $=230 \mathrm{~mm}$; and voxel size: $3.59 \times 3.59 \times 4.0 \mathrm{~mm}$-with an echo planar imaging factor of 39 and an acquisition time of $10 \min 9$ s per subject. For registration purposes, a T1-weighted anatomical image was also acquired: TR/TE: 8.8/4.05 ms; flip angle $=80^{\circ}$; matrix: $240 \times 240$; voxel size: $1 \times 1 \times 1 \mathrm{~mm}$; 180 axial slices; field of view $=240 \mathrm{~mm}$; and acquisition time $=1 \min 28 \mathrm{~s}$.

Functional images were pre- and post-processed with the Functional Magnetic Resonance Imaging of the Brain software library (FSL, version 5.0.8; FMRIB Analysis Group, Oxford University, UK). In brief, traditional preprocessing steps were performed: head motion, by realigning each volume to the middle volume; slice-timing correction; non-brain material extraction; spatial smoothing, using a $6 \mathrm{~mm}$ (full width at half maximum) kernel; highpass temporal filtering $(0.01 \mathrm{~Hz})$; and normalization to the Montreal Neurological Institute standard-space template (2-mm resolution). In addition, to reduce physiological noise, tissues were segmented by using the structural T1weighted images from each subject. The average white matter and cerebrospinal fluid signals were filtered using linear regression, the residuals of that analysis being used in the subsequent steps (Figure 1).

\section{ICA and dual regression}

Images were spatially and temporally decomposed in a four-dimensional (time $\times$ voxels) data matrix into a set of time courses and associated spatial maps with the multivariate exploratory linear decomposition into independent components interface of the FSL (Figure 1). This instrument was used as a primary approach to objectively identify resting state networks, especially the DMN for this study purpose $\mathrm{e}^{(11,12)}$. We performed two separate group ICA runs concatenating the time series of the individuals in each group.

For dual regression analysis (Figure 1), the set of spatial maps from the control group ICA was used as the

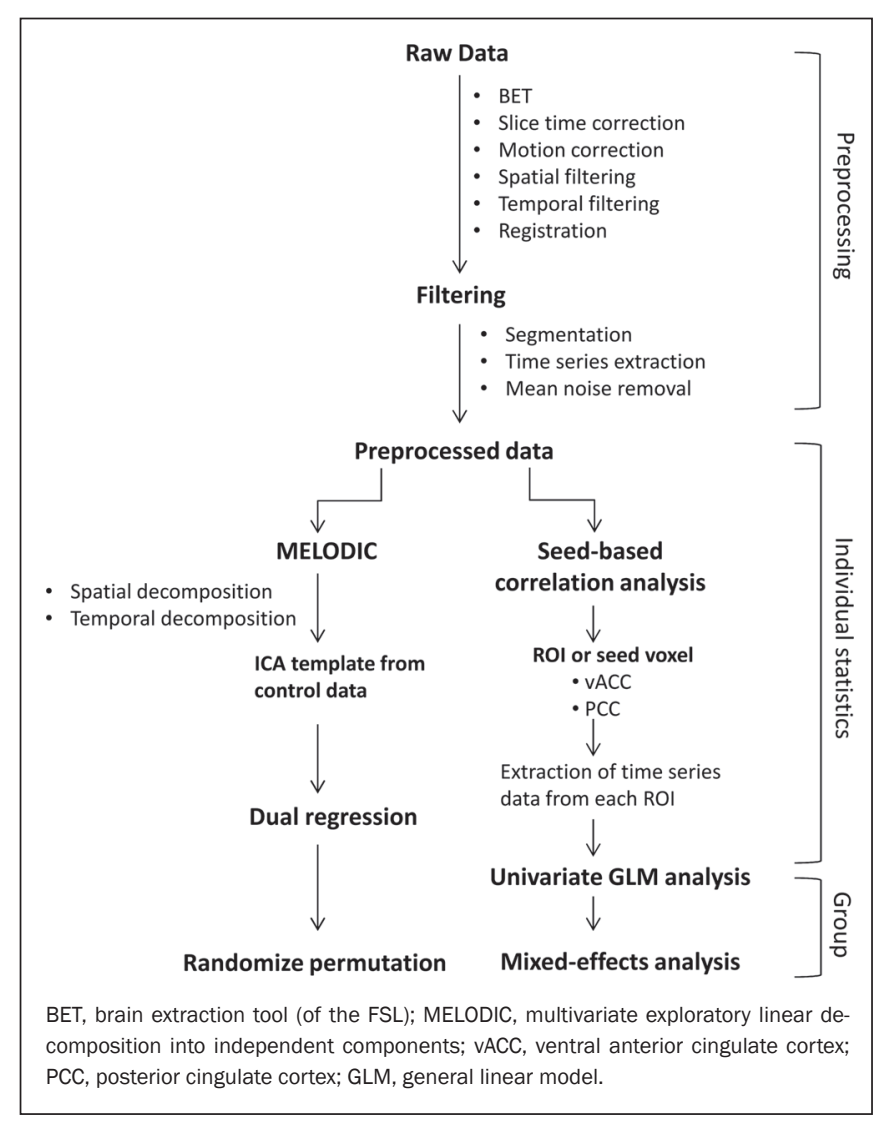

Figure 1. Flow chart of the data analysis process.

template, as described by Rytty et al. ${ }^{(13)}$, to generate subject-specific versions of the spatial maps, and associated time series ${ }^{(11-14)}$ were used in order to test for voxel-wise group differences. We adopted a nonparametric test, using the "randomize" permutation-testing tool of the FSL and calculating the maximum of 5,000 permutations, with a threshold of $p=0.05$ corrected for multiple comparisons throughout the brain.

\section{Seed-based correlation analysis}

The seed-based correlation analysis employed the same input data employed in the ICA ${ }^{(14,15)}$. The difference was that the seed-based correlation analysis was based on regions of interest (ROIs), as shown in Figure 1. The chosen ROIs and their Talairach coordinates were based on those that Greicius et al. ${ }^{(5)}$ defined as the main regions constituting the DMN. Thus, two ROIs (each $8 \mathrm{~mm}$ in diameter) were chosen, one centered in the posterior cingulate cortex (Talairach coordinates: $\mathrm{x}=2, \mathrm{y}=-51, \mathrm{z}=$ 27 ) and the other centered in the ventral anterior cingulate cortex (Talairach coordinates: $\mathrm{x}=2, \mathrm{y}=38, \mathrm{z}=-2$ ). For each participant, the signal extracted from those seed regions were input into two separate whole-brain analyses (one for each seed), allowing the positive and negative correlations to be evaluated. Correlation scores were converted to $z$-scores using Fisher's $z$-transformation. We performed group-level analyses using the mixed-effects model 
implemented in the fMRI Expert Analysis Tool of the FSL, adopting a voxel threshold of $z>2.3$ and correcting for multiple comparisons at the cluster level using Gaussian random field theory with a cluster significance threshold of $p=0.05$.

\section{RESULTS}

Baseline sociodemographic characteristics and patterns of drug use are presented in Table 1. All of the crackcocaine users were young (mean age, $29.1 \pm 10.6$ years), were male, typically had a low level of education (fewer than three years of schooling), were mostly unemployed, and were single. In addition, most of them were cigarette smokers. With the exceptions of age and marital status, the sociodemographic characteristics (including level of education, employment status, and tobacco use) differed between the crack-cocaine user group and the control group. Such differences were expected considering the impoverishment due to crack-cocaine addiction. On average, the subjects in the crack-cocaine user group had started using crack-cocaine at $22.6 \pm 8.9$ years of age, consumed $14.8 \pm$ 16.2 rocks per day, and had been abstinent for at least four weeks prior to the beginning of the experimental protocol (Table 1). All of the urine samples collected during the study period tested negative.

\section{rs-fMRI}

ICA

The ICA applied to the rs-fMRI data satisfactorily determined the component representing the DMN individually for subjects in the control and crack-cocaine user groups, accurately providing the mean for each group.
Neither the dual regression analyses considering the control group as the template nor the randomized permutation analyses identified any differences between the two groups.

\section{Seed-based correlation analysis}

Activities in the ventral anterior cingulate cortex (ROI centered at $\mathrm{x}=2, \mathrm{y}=38, \mathrm{z}=-2)$ and in the posterior cingulate cortex ( $\mathrm{ROI}$ centered at $\mathrm{x}=2, \mathrm{y}=-51, \mathrm{z}=27$ ), as depicted in Figure 2, were found to be positively and negatively related to the structures listed in Tables 2 and 3, respectively. No differences were found between the control and crack-cocaine user groups regarding the positive correlations. However, the Figure 3 shows the negative correlation between the ventral anterior cingulate cortex and the region corresponding to the left superior parietal lobule (Brodmann's area 5). As can be seen in Table 3, that correlation was greater in the crack-cocaine user group than in the control group $(p<0.0322)$.

\section{DISCUSSION}

In this study, we used ICA and seed-based correlation analysis to evaluate the functional connectivity of the DMN in crack-cocaine addicts. The seed-based correlation analysis showed that the negative or antiphasic relationship between the medial frontal site of the DMN and the superior parietal lobule was stronger in crack-cocaine addicts who had abstinent for at least four weeks than it was in age-matched non-drug-using control subjects.

Exploring the DMN and its connectivity in drug addiction has been of great interest to help improve the understanding of this complex disease ${ }^{(16)}$. Studies employing

Table 1-Sociodemographic characteristics and patterns of crack-cocaine use in a sample of male drug users, abstinent for at least four weeks, who underwent rs-fMRI in a 1.5 T scanner $(n=8)$, in comparison with age-matched non-drug-using male control subjects who also underwent rs-fMRI $(n=8)$.

\begin{tabular}{|c|c|c|c|c|}
\hline Characteristic & Non-drug-using controls & Crack-cocaine users & Statistic & $P$ \\
\hline Years of schooling, mean (SD) & $12.7(3.3)$ & $1.9(0.8)$ & $t(13)=9.14$ & $<0.0001$ \\
\hline Formal job & $6(75 \%)$ & $0(0 \%)$ & $\chi^{2}=14$ & 0.016 \\
\hline Informal job & $1(12.5 \%)$ & $0(0 \%)$ & & \\
\hline Unemployed & $0(0 \%)$ & $4(50 \%)$ & & \\
\hline On disability & $0(0 \%)$ & $1(12.5 \%)$ & & \\
\hline Not reported & $1(12.5 \%)$ & $1(12.5 \%)$ & & \\
\hline \multicolumn{5}{|l|}{ Marital status, $\mathrm{n}(\%)$} \\
\hline Single & $5(62.5 \%)$ & $6(75 \%)$ & $\chi^{2}=2.09$ & 0.35 \\
\hline Married & $3(37.5 \%)$ & $1(12.5 \%)$ & & \\
\hline \multicolumn{5}{|l|}{ Crack-cocaine use } \\
\hline Age, in years, at onset, mean (SD) & & $22.6(8.9)$ & & \\
\hline Amount consumed (rocks/day), mean (SD) & & $14.8(16.2)$ & & \\
\hline
\end{tabular}




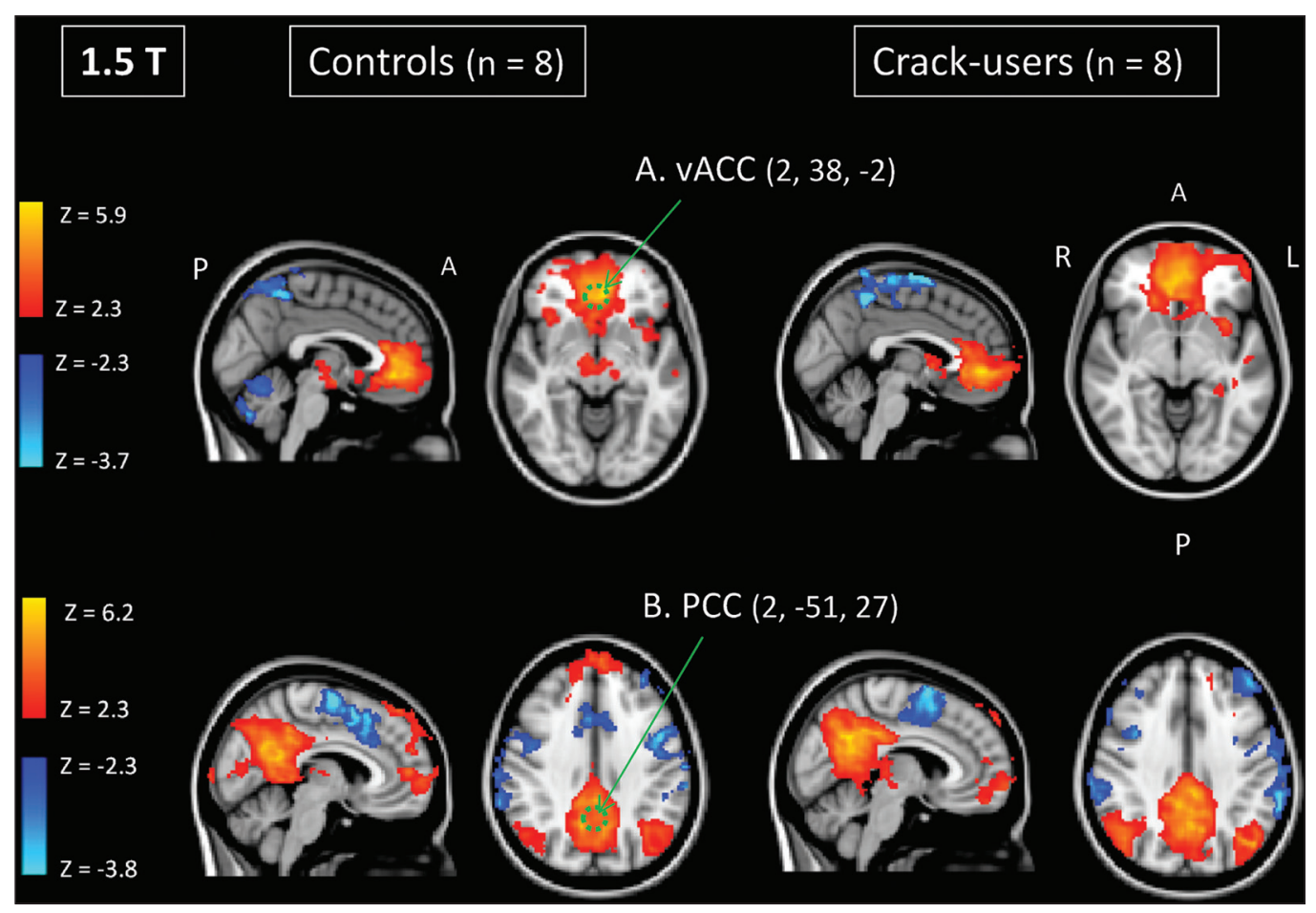

Figure 2. Functional connectivity determined by seed-based correlation analysis centering on ROls in an 8-mm diameter circle (depicted in green). In $\mathbf{A}$ the ventral anterior cingulate cortex (vACC: $x=2, y=$ $38, z=-2)$ and in $\mathbf{B}$ the posterio cingulate cortex (PCC: $x=2, y=$ $-51, z=27)$, considering the coordinates used by Greicius et al. ${ }^{(\mathbf{5})}$ on rs-fMRI scans of crack-cocaine users and age-matched non-drug using controls, obtained in $1.5 \mathrm{~T}$ scanners. $($ Red $/$ yellow $=$ positive correlation; blue/light blue = negative correlation).

Table 2-Regions positively related to ROIs ( $8 \mathrm{~mm}$ in diameter) centered in the ventral anterior cingulate cortex $($ Talairach coordinates: $\mathrm{x}=2, \mathrm{y}=38, \mathrm{z}=-2)$ and posterior cingulate cortex (Talairach coordinates: $x=2, y=-51, z=27$ ) in crack-cocaine users $(n=8)$ and age-matched non-drug-using controls ( $n=8$ ).

\begin{tabular}{|c|c|c|c|c|c|c|c|c|c|}
\hline \multirow[b]{2}{*}{ ROI } & \multirow[b]{2}{*}{ Group } & \multirow[b]{2}{*}{ Cluster } & \multirow[b]{2}{*}{ Voxels } & \multirow[b]{2}{*}{$\mathrm{P}$} & \multirow[b]{2}{*}{ Max. z } & \multicolumn{3}{|c|}{$\begin{array}{c}\text { Talairach } \\
\text { coordinates }\end{array}$} & \multirow[b]{2}{*}{ Brodmann's area } \\
\hline & & & & & & $x$ & $\mathrm{y}$ & z & \\
\hline \multirow[t]{4}{*}{ Ventral anterior cingulate cortex } & Control & 1 & 966 & 0.00152 & 3.89 & -56 & -12 & -16 & 21 (left middle temporal gyrus) \\
\hline & & 2 & 7,058 & $1.64 \times 10^{-16}$ & 5.61 & -6 & 40 & -8 & 10 (left medial frontal gyrus) \\
\hline & Crack-cocaine & 1 & 998 & 0.0012 & 3.87 & -48 & -2 & -26 & 20 (left inferior temporal gyrus) \\
\hline & & 2 & 8,499 & $7.68 \times 10^{-19}$ & 5.97 & 2 & 44 & -4 & 32 (right dorsal anterior cingulate) \\
\hline \multirow[t]{9}{*}{ Posterior cingulate cortex } & Control & 1 & 675 & 0.0268 & 4.39 & 56 & 0 & -22 & 21 (right middle temporal gyrus) \\
\hline & & 2 & 1,166 & 0.000885 & 4.27 & -8 & 66 & 6 & 10 (left superior frontal gyrus) \\
\hline & & 3 & 2,781 & $1.19 \times 10^{-7}$ & 4.39 & 30 & 28 & 58 & 6 (right middle frontal gyrus) \\
\hline & & 4 & 13,250 & $1.63 \times 10^{-23}$ & 5.95 & -4 & -52 & 28 & 31 (left dorsal posterior cingulate) \\
\hline & Crack-cocaine & 1 & 1,043 & 0.00197 & 4.26 & 68 & -2 & -10 & 21 (right middle temporal gyrus) \\
\hline & & 2 & 1,532 & $9.45 \times 10^{-5}$ & 4.77 & 0 & 64 & 4 & 10 (left medial frontal gyrus) \\
\hline & & 3 & 1,645 & $4.92 \times 10^{-5}$ & 5.61 & -46 & -70 & 34 & 39 (left angular gyrus) \\
\hline & & 4 & 1,824 & $1.8 \times 10^{-5}$ & 4.11 & -36 & 22 & 52 & 8 (left superior frontal gyrus) \\
\hline & & 5 & 15,337 & $4.92 \times 10^{-26}$ & 6.26 & -2 & -52 & 24 & 31 (left dorsal posterior cingulate) \\
\hline
\end{tabular}

rs-fMRI to investigate the effects or consequences of cocaine dependence have produced mixed results, from hyperconnectivity of the anterior cingulate $\operatorname{cortex}^{(17)}$ to decreases in connectivity between the DMN and other networks ${ }^{(18-21)}$.

The precise brain function supported by the DMN remains unknown. According to Raichle ${ }^{(6)}$, the DMN supports processes related to emotional processing (involving the ventral medial prefrontal cortex), self-referential mental activity (involving the dorsal medial prefrontal cortex), and the recollection of prior experiences (involving posterior elements of the DMN). The DMN is a functioning network that is never inactive; its level of activity seems to vary only according to the level of consciousness ${ }^{(22,23)}$. It remains active during mild sedation ${ }^{(24)}$, anesthesia ${ }^{(25)}$, and even during a vegetative state ${ }^{(26)}$, although with some variations of its connectivity ${ }^{(23)}$, and is completely silent only in brain death ${ }^{(26)}$. Therefore, it seems reasonable to consider that the DMN would be affected only under extremely life-threatening conditions, which fortunately might not be the case for crack users. In that sense, it is heartening to have found that the overall DMN connectivity in crack users is not yet affected in comparison with that observed in age-matched non-drug-using controls. 
Table 3-Regions negatively related to ROIs ( $8 \mathrm{~mm}$ in diameter) centered in the ventral anterior cingulate cortex (Talairach coordinates: $\mathrm{x}=2, \mathrm{y}=38, \mathrm{z}=-2)$ and posterior cingulate cortex (Talairach coordinates: $x=2, y=-51, z=27$ ) in crack-cocaine users $(n=8)$ and age-matched non-drug-using controls ( $n=8$ ).

\begin{tabular}{|c|c|c|c|c|c|c|c|c|c|}
\hline \multirow[b]{2}{*}{ ROI } & \multirow[b]{2}{*}{ Group or comparison } & \multirow[b]{2}{*}{ Cluster } & \multirow[b]{2}{*}{ Voxels } & \multirow[b]{2}{*}{$\mathrm{P}$} & \multirow[b]{2}{*}{ Max z } & \multicolumn{3}{|c|}{$\begin{array}{c}\text { Talairach } \\
\text { coordinates }\end{array}$} & \multirow[b]{2}{*}{ Brodmann's area or region } \\
\hline & & & & & & $x$ & $\mathrm{y}$ & z & \\
\hline \multirow[t]{7}{*}{ Ventral anterior cingulate cortex } & Control & 1 & 581 & 0.0334 & 3.46 & -22 & 2 & 70 & 6 (left superior frontal gyrus) \\
\hline & & 2 & 1,643 & $1.55 \times 10^{-5}$ & 3.79 & 22 & 2 & 62 & 6 (right superior frontal gyrus) \\
\hline & & 3 & 4,675 & $2.85 \times 10^{-12}$ & 3.52 & 2 & -74 & -38 & Right inferior semilunar lobule \\
\hline & & 4 & 4,756 & $1.99 \times 10^{-12}$ & 3.64 & -24 & -64 & 46 & 7 (left superior parietal lobule) \\
\hline & Crack-cocaine & 1 & 12,432 & $1.31 \times 10^{-24}$ & 4.42 & -2 & -10 & 72 & 6 (left medial frontal gyrus) \\
\hline & Group-level analysis & & & & & & & & \\
\hline & Crack-cocaine $>$ control & 1 & 585 & 0.0322 & 3.66 & -32 & -38 & 60 & 5 (left superior parietal lobule) \\
\hline \multirow[t]{6}{*}{ Posterior cingulate cortex } & Control & 1 & 655 & 0.0312 & 3.94 & -34 & 44 & 34 & 9 (left middle frontal gyrus) \\
\hline & & 2 & 9,727 & $6.21 \times 10^{-19}$ & 4.52 & 2 & 14 & 50 & 6 (right superior frontal gyrus) \\
\hline & Crack-cocaine & 1 & 2,049 & $5.3 \times 10^{-6}$ & 4.53 & 58 & -28 & 30 & 40 (right inferior parietal lobule) \\
\hline & & 2 & 2,381 & $9.54 \times 10^{-7}$ & 4.54 & -42 & 56 & 22 & 10 (left middle frontal gyrus) \\
\hline & & 3 & 2,719 & $1.79 \times 10^{-7}$ & 4.49 & 30 & 48 & 26 & 10 (right superior frontal gyrus) \\
\hline & & 4 & 6,607 & $2.21 \times 10^{-14}$ & 4.46 & -64 & -36 & 30 & 40 (left inferior parietal lobe) \\
\hline
\end{tabular}

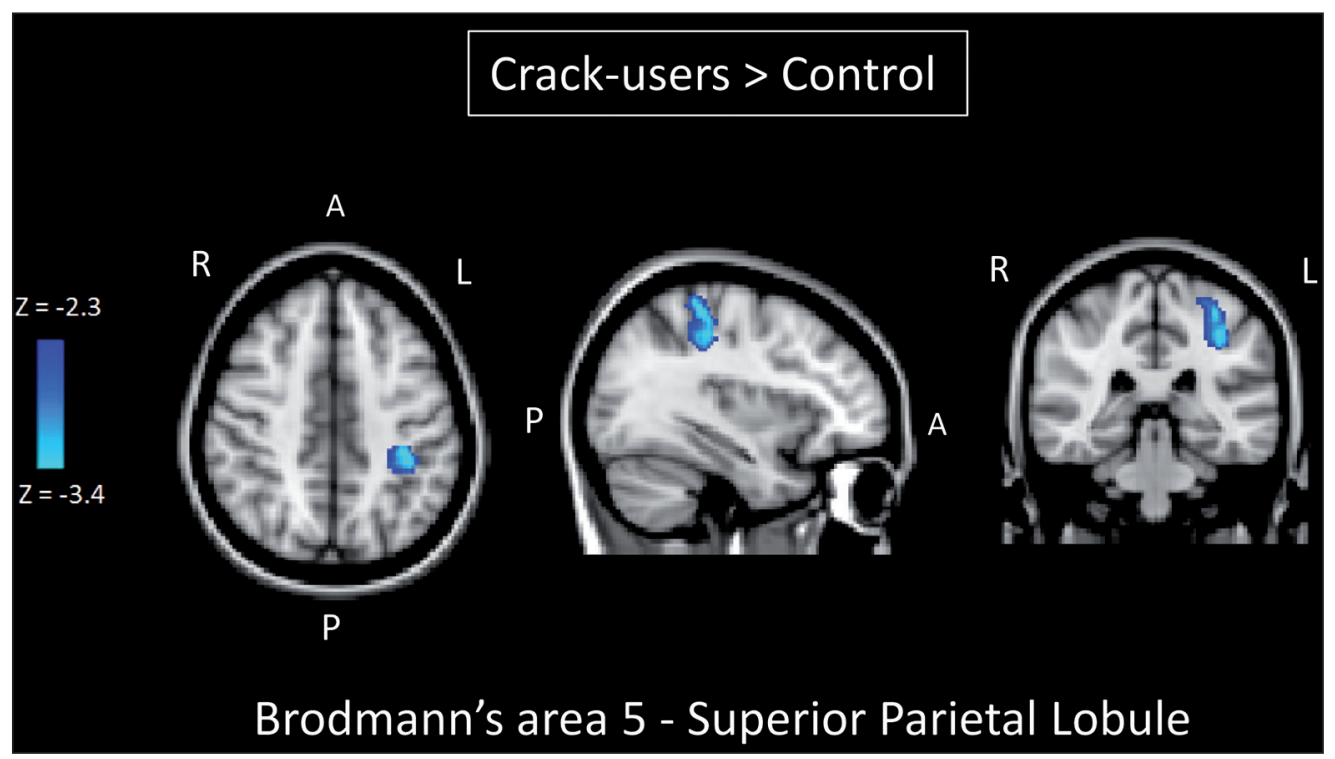

Figure 3. Group-level comparison of negative correlations between crackcocaine users and age-matched nondrug-using controls determined by seed-based correlation analysis of the ROI centered in the ventral anterior cingulate cortex $(x=2, y=38$, $z=-2)$ and the region $(x=-32, y=$ $-38, z=60$ ) corresponding to the left superior parietal lobule (Brodmann's area 5). The negativity was greater ( $p$ $<0.0322$ ) in the crack-cocaine users when compared to the non-drug-using control subjects. From left to right: axial, sagittal and coronal planes. (Blue/light blue $=$ difference of negative correlation).

Consequently, although the use of crack is highly detrimental to our young patients in many ways, there is hope that there will be a good recovery, given that intrinsic brain functioning is preserved or re-established after abstinence.

Compulsive cocaine use has been associated with a balance between increased striatal-anterior prefrontal/ orbitofrontal connectivity and decreased striatal-dorsal anterior cingulate connectivity ${ }^{(27)}$. In the present study, the seed-based correlation analysis showed that negative connectivity between the ventral anterior cingulate cortex and the left superior parietal lobule was greater in crack-cocaine users. This brain area, corresponding to Brodmann's area 5, is situated immediately posterior to the primary somatosensory areas (postcentral gyrus), anterior and to the right of Brodmann's area 7. The superior parietal lobule has been proven to be necessary for the executive rearrangement of information in working memory ${ }^{(28)}$, impairment of the connectivity between the medial frontal region and the superior parietal lobule observed here in crack-cocaine users, thus potentially being strictly related to the severe executive dysfunction typically seen in crackcocaine dependent subjects ${ }^{(29)}$, a condition that aggravates and maintains the drug addiction ${ }^{(2,3,30)}$. Albeit intriguing, this result needs to be interpreted with great caution and confirmed in a larger sample, especially considering that the veracity of the "negativity" between network relationships is highly uncertain and is still a matter of debate ${ }^{(31)}$.

This study has certain limitations. We included data from a small number of subjects. Although data from a larger sample were collected, many of the subjects had to be excluded because of technical issues such as artifacts and large head movements. This study was focused only 
on the analysis of the DMN as the principal resting state network of interest. Therefore, in this exploratory study, the total DMN functional connectivity determined by ICA was found to be preserved in crack-cocaine dependent subjects who had been abstinent for at least four weeks in comparison with that observed for age-matched non-drugusing controls. However, the negative connectivity between the superior parietal lobule and the ventral anterior cingulate cortex in crack-cocaine users was greatest when we performed seed-based correlation analysis with a single metric of functional connectivity. Our results suggest that, in crack-cocaine addiction, the DMN is intrinsically unaffected, although there might be restricted functional connectivity with a region extrinsically related to the DMN.

\section{Acknowledgments}

We would like to thank Dr. Luis Henrique Casagrande, Elton Francisco Pavan Batista, and José Luiz Aranda.

\section{REFERENCES}

1. Duailibi LB, Ribeiro M, Laranjeira R. Profile of cocaine and crack users in Brazil. Cad Saude Publica. 2008;24 Suppl 4:s545-57.

2. Koob GF, Volkow ND. Neurocircuitry of addiction. Neuropsychopharmacology. 2010;35:217-38.

3. Volkow ND, Wang GJ, Fowler JS, et al. Addiction circuitry in the human brain. Annu Rev Pharmacol Toxicol. 2012;52:321-36.

4. Volkow ND, Wang GJ, Fowler JS, et al. Addiction: decreased reward sensitivity and increased expectation sensitivity conspire to overwhelm the brain's control circuit. Bioessays. 2010;32:748-55.

5. Greicius MD, Krasnow B, Reiss AL, et al. Functional connectivity in the resting brain: a network analysis of the default mode hypothesis. Proc Natl Acad Sci U S A. 2003;100:253--8.

6. Raichle ME. The brain's default mode network. Annu Rev Neurosci. 2015;38:433-47.

7. Raichle ME, Snyder AZ. A default mode of brain function: a brief history of an evolving idea. Neuroimage. 2007;37:1083-90; discussion 1097-9.

8. Rosazza C, Minati L. Resting-state brain networks: literature review and clinical applications. Neurol Sci. 201 1;32:773-85.

9. Raichle ME, MacLeod AM, Snyder AZ, et al. A default mode of brain function. Proc Natl Acad Sci U S A. 2001;98:676-82.

10. Ma N, Liu Y, Fu XM, et al. Abnormal brain default-mode network functional connectivity in drug addicts. PLoS One. 201 1;6:e16560.

11. Beckmann CF. Modelling with independent components. Neuroimage. 2012;62:891-901.

12. Beckmann CF, Smith SM. Probabilistic independent component analysis for functional magnetic resonance imaging. IEEE Trans Med Imaging. 2004;23:137-52.

13. Rytty R, Nikkinen J, Paavola L, et al. GroupICA dual regression analysis of resting state networks in a behavioral variant of frontotemporal dementia. Front Hum Neurosci. 2013;7:461.

14. Smith DV, Utevsky AV, Bland AR, et al. Characterizing individual differences in functional connectivity using dual-regression and seed-based approaches. Neuroimage. 2014;95:1-12.

15. Joel SE, Caffo BS, van Zijl PC, et al. On the relationship between seed-based and ICA-based measures of functional connectivity. Magn Reson Med. 2011;66:644-57.

16. Sutherland MT, McHugh MJ, Pariyadath V, et al. Resting state functional connectivity in addiction: lessons learned and a road ahead. Neuroimage. 2012;62:2281-95.

17. Camchong J, MacDonald AW 3rd, Nelson B, et al. Frontal hyperconnectivity related to discounting and reversal learning in cocaine subjects. Biol Psychiatry. 2011;69:1117-23.

18. Gu H, Salmeron BJ, Ross TJ, et al. Mesocorticolimbic circuits are impaired in chronic cocaine users as demonstrated by resting-state functional connectivity. Neuroimage. 2010;53:593-601.

19. Liang X, He Y, Salmeron BJ, et al. Interactions between the salience and default-mode networks are disrupted in cocaine addiction. J Neurosci. 2015;35:8081-90.

20. Kelly C, Zuo XN, Gotimer K, et al. Reduced interhemispheric resting state functional connectivity in cocaine addiction. Biol Psychiatry. 2011;69:684-92.

21. Ding X, Lee SW. Cocaine addiction related reproducible brain regions of abnormal default-mode network functional connectivity: a group ICA study with different model orders. Neurosci Lett. 2013;548:110-4.

22. Boveroux P, Bonhomme V, Boly M, et al. Brain function in physiologically, pharmacologically, and pathologically altered states of consciousness. Int Anesthesiol Clin. 2008;46:131-46.

23. Vanhaudenhuyse A, Noirhomme Q, Tshibanda LJ, et al. Default network connectivity reflects the level of consciousness in noncommunicative brain-damaged patients. Brain. 2010;133:161-71.

24. Greicius MD, Kiviniemi V, Tervonen O, et al. Persistent defaultmode network connectivity during light sedation. Hum Brain Mapp. 2008;29:839-47.

25. Buckner RL, Vincent JL. Unrest at rest: default activity and spontaneous network correlations. Neuroimage. 2007;37:1091-9.

26. Boly M, Tshibanda L, Vanhaudenhuyse A, et al. Functional connectivity in the default network during resting state is preserved in a vegetative but not in a brain dead patient. Hum Brain Mapp. 2009;30:2393-400.

27. Hu Y, Salmeron BJ, Gu H, et al. Impaired functional connectivity within and between frontostriatal circuits and its association with compulsive drug use and trait impulsivity in cocaine addiction. JAMA Psychiatry. 2015;72:584-92.

28. Koenigs M, Barbey AK, Postle BR, et al. Superior parietal cortex is critical for the manipulation of information in working memory. J Neurosci. 2009;29:14980-6.

29. Fein G, Di Sclafani V, Meyerhoff DJ. Prefrontal cortical volume reduction associated with frontal cortex function deficit in 6-week abstinent crack-cocaine dependent men. Drug Alcohol Depend. 2002;68:87-93.

30. Goldstein RZ, Volkow ND. Dysfunction of the prefrontal cortex in addiction: neuroimaging findings and clinical implications. Nat Rev Neurosci. 201 1;12:652-69.

31. Cole DM, Smith SM, Beckmann CF. Advances and pitfalls in the analysis and interpretation of resting-state FMRI data. Front Syst Neurosci. 2010;4:8.

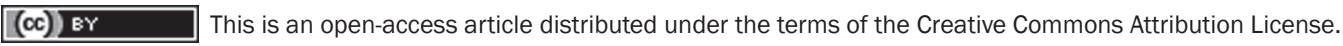

